\title{
A PESCA DO CAMARÃO-SETE-BARBAS Xiphopenaeus kroyeri NO MUNICÍPIO DE CANANÉIA - SP ENTRE 1998 E 1999
}

\author{
MENDONÇA, J.T. ${ }^{1}$ \& E. BARBIERI² \\ ${ }^{1}$ Instituto de Pesca - SAA - Núcleo de Pesquisa do Litoral Sul - Av. Prof. Besnard,s/ \\ nº, Cx. Postal 61, CEP 11990-000 - Cananéia, SP, E-mail: cananeia@rgt.matrix.com.br; \\ ${ }^{2}$ Centro Universitário São Camilo. Av. Nazaré, 1501. Ipiranga. São Paulo. E-mail: \\ edisonbarbieri@zipmail.com, Apoio : Prefeitura Municipal de Ilha Comprida e Fundo \\ Estadual de Recursos Hídricos - SRHSO
}

\begin{abstract}
RESUMO
A pesca de Cananéia tem o camarão-sete-barbas como principal produto desembarcado. O trabalho foi desenvolvido no litoral sul do Estado de São Paulo, no período de 1998 e 1999 , coletando dados de produção, esforço e valor econômico do camarão-sete-barbas. A produção média desembarcada de camarão-sete-barbas no município de Cananéia, nos anos estudados foi de 728 toneladas anuais. As categorias de comércio estão divididas entre camarão-sete-barbas bruto (sem seleção a bordo), camarão-sete-barbas escolhido (com seleção), camarão-setebarbas descabeçado (com seleção e posterior processamento) e camarão-sete-barbas miúdo (com seleção, sendo retirado os maiores). Os maiores desembarques ocorreram no primeiro semestre e o segundo semestre se caracterizou pela maior produção de camarão escolhido. Os resultados mostraram que as capturas de camarão-sete-barbas estão em declínio, sugerindo pouca eficiência da portaria que estabelece o defeso da espécie para a conservação do recurso. A análise da composição da rejeição junto à pesca artesanal é necessária, com o intuito de melhorar a administração pesqueira e o aproveitamento racional das capturas.
\end{abstract}

Palavras chave: Pesca, camarão, Brasil

\section{THE FISHING OF BOB SHRIMP Xiphopenaeus kroyeri IN CANANÉIA DISTRICT (SP) - BETWEEN 1998 AND 1999}

\begin{abstract}
The fishery of Cananéia (São Paulo, Brazil) is dominated by catches of the sea bob shrimp Xiphopenaeus kroyeri. The work was developed in the southern coast of São Paulo State, between 1998 and 1999 and included collecting production, capture effort and economic value data of the Xiphopenaeus kroyeri. Mean landings of shrimp in the municipal district of Cananéia have been approximately 728 tons/year. The trade categories are divided into gross shrimp (without selection on board), chosen shrimp (with selection), clean shrimp (with selection and posterior processing) and small shrimp (after selection of larger ones). Largest landings occurred in the first semester and the second semester was characterized by the largest production of chosen shrimp. The results suggest presented that the fishery is declining, and do not agree with the current period of closure. The analysis of the by-catch composition of artesanal fishery is necessary, in order to improve the fishing administration and the rational use of the resource.
\end{abstract}

Keyword: Fishing, shrimp, Brazil 


\section{INTRODUÇÃO}

A pesca dos camarões peneídeos vem sendo incrementada desde os anos 1950, sofrendo uma exploração muito grande em todo o mundo (Garcia \& Le Reste, 1987). No Brasil, a pesca do camarão-sete-barbas Xiphopenaeus kroyeri teve seu início há 30 anos, inicialmente artesanal e paulatinamente industrial, utilizando embarcações com dimensões acima de 16 metros de comprimento e de arrasto duplo. As maiores produções ocorreram na década de 1980, sendo que o camarão-sete-barbas chegou a compor $50 \%$ dos desembarques totais dos camarões na região sudeste-sul (Valentini et al, 1991).

Na região de Cananéia a pesca se desenvolveu a partir do final da década de 1970. As capturas ocorreram através de barcos camaroneiros de diferentes proporções, utilizando tangones (arrasto duplo) e arrasto de popa (arrasto simples) (Mendonça, 1998). Estas capturas foram classificadas em duas categorias: pesca de camarão-sete-barbas bruto, não possuindo nenhum tipo de seleção por tamanho, a bordo; e a pesca do camarão-sete-barbas escolhido, quando há seleção da captura a bordo. Neste último, a embarcação pode ou não trazer o camarão menor (selecionado) para desembarcar, dependendo da oportunidade de comércio (Severino-Rodrigues et al, 1992; Mendonça, op. cit.).

Nos últimos anos, os desembarques de camarão-sete-barbas no Estado de São Paulo vêm declinando, causando o direcionamento de pescadores para outros recursos, quando estes podem, ou acarreta problemas sociais aos pescadores que não têm condições financeiras para trabalharem em outros tipos de pescarias. Historicamente o camarão-sete-barbas em Cananéia é o principal produto desembarcado (Mendonça, op. cit.), sendo uma grande fonte de renda para a população. Assim, o acompanhamento do comportamento da pesca deste recurso é de extrema importância, pois qualquer modificação da atividade poderá acar- retar problemas sócio-econômicos para o município e região.

Este estudo visa diagnosticar as capturas do camarão-sete-barbas em Cananéia, com o intuito de verificar as possíveis influências do comportamento destas capturas sobre o estoque de camarão do litoral sul do Estado de São Paulo, durante o período de 1998 e 1999, bem como analisar a atividade pesqueira sobre 0 recurso.

\section{MATERIAL E MÉTODOS}

Analisaram-se os desembarques do camarão-sete-barbas no município de Cananéia, litoral sul do Estado de São Paulo (figura 1), durante os anos de 1998 e 1999. A produção foi obtida através de entrevistas com os pescadores e/ou mestres das embarcações durante os desembarques, coletando dados de produção total e por espécie desembarcada, esforço (em dias efetivos de pesca), local e profundidade de pesca, e ponto de desembarque (Haimovici \& Mendonça, 1996a; Perez et al, 1998). Tentou-se realizar a entrevista em todos os desembarques, sendo que as embarcações que não foi possível realizar a entrevista, obtivemos apenas os dados de produção através das anotações de movimento de descarga dos pontos de desembarque. Para as embarcações de menor porte (bateiras), quando não foi possível realizar as entrevistas, devido a rapidez com que o desembarque se procedeu, a coleta de produção realizou-se através dos pontos de escoamento, diferenciando-se de acordo com as categorias de pesca (Mendonça, 1998). Com esta metodologia todos os desembarques de camarão-sete-barbas no município de Cananéia foram registrados, atingindo 1289 desembarques de camarão-sete-barbas em 1998 e 1812 desembarques em 1999.

Durante os desembarques, tomou-se amostras de 500 gramas de camarão-sete-barbas, a fim de obter a distribuição de comprimento, sendo medido o comprimento do cefalotórax e estimando o comprimento total 
conforme Mendonça (1998). Utilizou-se o banco de dados ProPesq ${ }^{\circledR}$ do Instituto de Pesca da Secretaria de Agricultura e Abastecimento do Estado de São Paulo (Ávila-da-Silva et al., 1999) para todas totalizações de produção, variações dos valores do pescado e distribuição de comprimento dos camarões, juntamente com a planilha analítica para organização dos dados.

A distribuição de comprimento foi extrapolada para a produção total do município, estimando a quantidade de camarão desembarcado para cada classe de comprimento, estando dividida em trimestres. Para a análise de comprimentos mais explorados $\left(\mathrm{L}_{50}\right)$ foram realizadas a distribuição acumulada de comprimento anual das capturas.

Utilizou-se a terminação de camarãosete-barbas bruto para os desembarques de camarão sem seleção a bordo e de camarãosete-barbas escolhido para desembarque que tiveram seleção dos maiores exemplares, visto que estas categorias existem devido a necessidade de obter melhores produtos para comercialização, sendo que indivíduos maiores atingem melhor valor no mercado.

\section{DESCRIÇÃO DA FROTA ARRASTEIRA DE CANANÉIA}

Mendonça (1998) classificou a frota pesqueira do município em diferentes categorias, estando as embarcações que atuam sobre a o camarão-sete-barbas da categoria de pesca de mar-a-fora (embarcações maiores) e na pesca costeira (de embarcações menores). Assim, diferenciaremos as embarcações de acordo com o tamanho, sendo a seguinte:--botes e - -

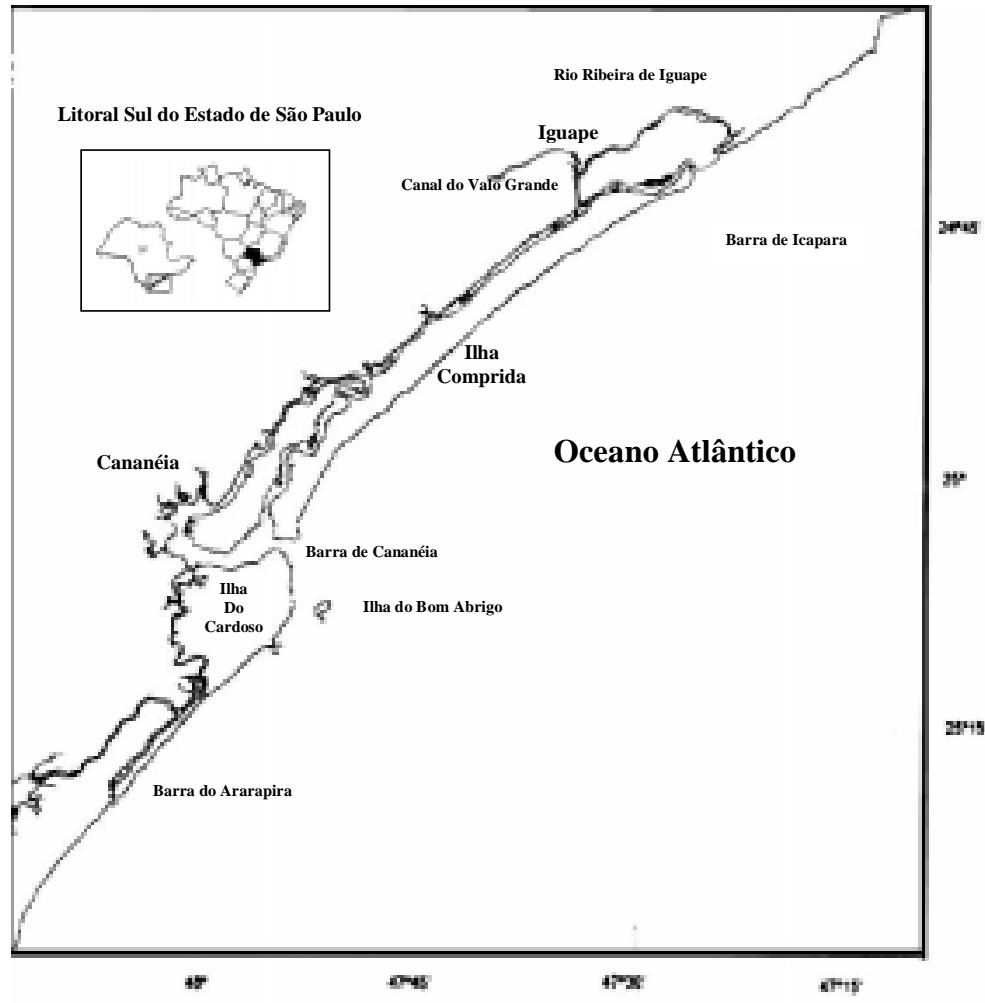

Figura 1. Mapa da região estudada, litoral sul do Estado de São Paulo - Brasil 
- bateiras, sendo embarcações de madeira com comprimentos entre 7 e 9 metros, com motores de 11 a 18 HP e autonomia de mar em torno de 4 dias, sendo que não trabalham à noite. As profundidades trabalhadas, geralmente não ultrapassam os 13 metros e podem usar o arrasto de popa (uma rede) ou com tangones (duas redes). As dimensões das redes são de 3 a 4 metros de abertura horizontal e $7 \mathrm{~m}$ de comprimento total. Tais embarcações trabalham praticamente com o camarão-sete-barbas escolhido durante todo o ano.

- Baleeiras, também de madeira com comprimentos entre 10 e 16 metros, motores de 97 a $115 \mathrm{HP}$ e autonomia de mar acima de 5 dias, podendo trabalhar à noite. As profundidades trabalhadas ficam entre 5 até 17 metros, com tangones. As redes utilizadas apresentam abertura horizontal que varia de 11 a 17 metros e comprimentos acima de 20 metros. Seus desembarques são de camarão-sete-barbas bruto e/ou escolhido.

Estas embarcações são típicas do litoral do Estado de São Paulo, principalmente para captura de camarões (Assumpção et al., 1996; Tiago et al, 1995; Mendonça, 1998), sendo todas mecanizadas, com sua ação dependendo das condições climáticas para trabalharem.

\section{RESULTADOS E DISCUSSÃO}

Historicamente, Cananéia tem o camarão-sete-barbas como principal produto pesqueiro, com as maiores produções na década de 1980 (Mendonça, 1998). Atualmente, ainda é o principal recurso pesqueiro explorado, entretanto no ano de 1999, ocorreram desembarques significativos de peixes, e uma pequena diminuição das capturas de camarão-sete-barbas. Durante os anos de 1998 e 1999 foram desembarcados 869 e 589 toneladas de camarão-sete-barbas, respectivamente, totalizando 54\% em 1998 e 28\% em 1999 de toda a produção pesqueira do município (tabela 1).
Em 1998, o camarão-sete-barbas bruto atingiu 816 t. desembarcadas, compondo 94\% da produção total de camarão e o escolhido 53 t. $(6 \%)$, sendo que, da produção total de camarão-sete-barbas, $11 \%$ proveio da pesca de botes e bateiras e 89\% das baleeiras. Em 1999, os desembarques foram divididos em 4 categorias: camarão bruto 467 t. (79\% dos desembarques de camarão-sete-barbas), camarão escolhido com 121 t. (20\%), camarão miúdo e camarão descabeçado 384 kg (1\%). Desta produção $15 \%$ foram desembarques da pesca com botes e bateiras e $85 \%$ com baleeiras. Os desembarques de camarão miúdo e descabeçado foram pequenos, não afetando as análises das capturas, mas devem ser mencionados, mostrando que os pescadores tendem a agregar valor no produto (com o camarão descabeçado) ou aproveitar produtos que, geralmente são descartados (camarão miúdo) visando aumentarem a renda.

Os desembarques de camarão ocorreram ao longo de todo o ano interrompendo-se durante o período de defeso (portaria $\mathrm{n}^{\circ} 021$ de 11 de fevereiro de 1999), sendo que o camarão bruto foi desembarcado em maiores quantidades no primeiro semestre, diminuindo ao longo do ano (figura 2). Já o camarão-sete-barbas escolhido teve maiores desembarques no segundo semestre (figura 3). Cabe salientar que as embarcações menores (botes e bateiras), geralmente desembarcam o camarão escolhido e as embarcações maiores, apenas desembarcaram tal categoria no segundo semestre. Neste período há índices elevados de rejeição a bordo, devido ao descarte de camarões miúdos, portanto urge a necessidade de se saber o quanto é rejeitado, a fim de subsidiar uma futura administração pesqueira (Haimovici \& Mendonça, 1996b), com a finalidade de se obter uma exploração sustentável do recurso. De acordo com os pescadores, a proporção de camarão rejeitado fica em torno de três quilos de camarão-sete-barbas rejeitado para cada quilo de camarão aproveitado. Graça-Lopes (1996) coloca que a eficiência de embarcações acima de 14 metros de comprimento é quatro 
vezes superior que as menores, possibilitando trabalhar sobre o camarão bruto ao longo do ano, cujo valor é mais baixo, mas compensa pela maior produção. Quando estas diminuem a pescaria tende a incidir sobre o camarão escolhido, que apresenta valor maior, acarretando, desta forma o aumento de desembarques deste camarão no segundo semestre. A rejeição de camarões neste período ocorre, também devido a maior disponibilidade de indivíduos maiores, pois esta época mostra-se ser o principal período de desova, havendo maior concentração dos indivíduos (SeverinoRodrigues et al, 1992; Graça-Lopes, op. cit.).

Na pesca de camarão bruto, os indivíduos menores (classe de comprimento de 3,0 a $6,0 \mathrm{~cm}$ ) ocorreram no primeiro e segundo trimestres. Os maiores exemplares foram pescados no segundo semestre (figura 4). No início do ano, desembarques de pequenos indivíduos, possivelmente indiquem o principal período de recrutamento da espécie (Graça-Lopes, 1996; Mendonça, 1998). No primeiro semestre há maiores produções, fazendo com que não

Tabela 1. Produção pesqueira total desembarcada em quilogramas, no município de Cananéia durante 1998

\begin{tabular}{|c|c|c|c|c|c|c|c|c|c|c|c|c|c|c|}
\hline Produto & JAN & FEV & MAR & ABR & MAI & JUN & JUL & AGO & SET & OUT & NOV & DEZ & TOTAL & $\%$ \\
\hline \multicolumn{15}{|l|}{ Teleósteos } \\
\hline Abrótea & & & & & & & & 6 & 28 & & & & 34 & 0,0 \\
\hline Anchova & 6 & & 2 & 49 & & 34 & 785 & 52 & & & 34 & 340 & 1301 & 0,1 \\
\hline Badejo & & & & & & 3 & 3 & & 4 & 2 & 4 & & 16 & 0,0 \\
\hline Bagre & 84 & 403 & 646 & 740 & 407 & 331 & 131 & 534 & 136 & 27 & 1584 & 413 & 5437 & 0,3 \\
\hline Betara & 7853 & 5416 & 9633 & 4225 & 3237 & 1295 & 2852 & 1921 & 2484 & 1008 & 5596 & 6936 & 52455 & 3,3 \\
\hline Bonito & & & & & & & & & & & & 79 & 79 & 0,0 \\
\hline Caranha & 39 & 57 & 14 & & 3 & & & & 56 & & 17 & & 185 & 0,0 \\
\hline Carapeba & 9 & & 4 & & 2 & 66 & 16 & & 40 & 109 & 857 & 853 & 1956 & 0,1 \\
\hline Cascote & & & 585 & 394 & 147 & 85 & 25 & 70 & 6 & 8 & 108 & 402 & 1830 & 0,1 \\
\hline Cioba & & & & & & & & 94 & & & & & 94 & 0,0 \\
\hline Congro-rosa & 35 & & & & & & & 29 & & & & & 64 & 0,0 \\
\hline Corvina & 9384 & 1489 & 3560 & 2650 & 2984 & 4926 & 5195 & 2986 & 2935 & 2196 & 7404 & 4505 & 50213 & 3,1 \\
\hline Dourado & & 4 & & & & & & & 12 & & & & 16 & 0,0 \\
\hline Garoupa & 198 & 147 & 249 & 845 & 128 & 41 & 9 & 96 & 65 & & 55 & 176 & 2008 & 0,1 \\
\hline Goete & 93 & 40 & 411 & 154 & 803 & 265 & 50 & 124 & & & 35 & 80 & 2054 & 0,1 \\
\hline Linguado & 16 & & 1 & & 22 & 335 & 323 & 503 & 413 & 515 & 1252 & 157 & 3537 & 0,2 \\
\hline Manjuba & & & & & & & & & & & 400 & & 400 & 0,0 \\
\hline Marlin & & & 30 & & & & & & & & & & 30 & 0,0 \\
\hline Mero & 5 & & 13 & & & 181 & 26 & & 2 & & 108 & 19 & 354 & 0,0 \\
\hline Miraguaia & 3 & & 26 & & 7 & 902 & 120 & 85 & & 40 & & & 1182 & 0,1 \\
\hline Mistura * & 4404 & 2902 & 2774 & 3998 & 2864 & 1597 & 1392 & 6195 & 4829 & 3177 & 7866 & 7873 & 49870 & 3,1 \\
\hline Pampano & & & & & & & & & & & 20 & 39 & 59 & 0,0 \\
\hline Parati & 609 & 1393 & 5641 & 5685 & 2967 & 2048 & 1810 & 370 & 1540 & 1216 & 4758 & 2324 & 30362 & 1,9 \\
\hline Paru & 8 & 204 & 16 & & & & & & 16 & & & 36 & 279 & 0,0 \\
\hline Peixe-espada & 22 & 411 & 564 & 473 & 433 & 273 & 261 & 46 & 79 & 42 & 6 & 503 & 3113 & 0,2 \\
\hline Peixe-galo & & & 3 & & & & & & & & 3 & 264 & 269 & 0,0 \\
\hline Peixe-porco & 52 & 351 & 12 & & & & & 80 & 42 & & 369 & 455 & 1361 & 0,1 \\
\hline Pescada & 1493 & 194 & 2 & 639 & & & 742 & & & & 174 & 88 & 3331 & 0,2 \\
\hline Pescada-amarela & 141 & 90 & 38 & 20 & 26 & 106 & 96 & 117 & 37 & 14 & 815 & 711 & 2210 & 0,1 \\
\hline Pescada-banana & 119 & 62 & 4 & & & & & & & 20 & & 182 & 387 & 0,0 \\
\hline Pescada-bicuda & & 14 & & & 5 & 15 & & & & & & 23 & 57 & 0,0 \\
\hline Pescada-branca & 518 & 635 & 882 & 329 & 559 & 145 & 101 & 27 & 12 & 18 & 364 & 403 & 3993 & 0,2 \\
\hline Pescada-cambucu & 103 & 257 & 302 & 163 & 371 & 214 & 30 & 60 & 10 & & 37 & 503 & 2048 & 0,1 \\
\hline Pescada-foguete & 15973 & 9964 & 19899 & 16937 & 23028 & 14339 & 22942 & 21798 & 27202 & 12460 & 42609 & 43309 & 270461 & 16,8 \\
\hline Pescada-jaguara & & & & & & 30 & 7 & & 2 & 7 & & & 46 & 0,0 \\
\hline Pescada-olhuda & 542 & 303 & 362 & 277 & 120 & 361 & 377 & 225 & 89 & 264 & 700 & 614 & 4234 & 0,3 \\
\hline Pescadinha & 32 & 58 & 1 & 1 & 23 & 202 & 90 & 84 & 75 & 15 & & 16 & 598 & 0,0 \\
\hline Prejereba & 170 & 9 & 98 & 960 & 204 & 21 & 40 & 19 & 57 & 32 & 518 & 405 & 2532 & 0,2 \\
\hline Robalão & & & & & & & & & & & 8 & 3 & 11 & 0,0 \\
\hline Robalete & 36 & 19 & 83 & 47 & 45 & 39 & 16 & 16 & 3 & 9 & 40 & 37 & 390 & 0,0 \\
\hline Robalo & 403 & 195 & 242 & 102 & 150 & 133 & 99 & 91 & 210 & 262 & 654 & 85 & 2626 & 0,2 \\
\hline Robalo-peva & & & & & & & & & & & & 7 & 7 & 0,0 \\
\hline Salgo & 4 & 11 & 7 & & & & & 7 & 5 & & & 18 & 52 & 0,0 \\
\hline Salteira & 2772 & 2973 & 3714 & 2179 & 1911 & 1915 & 1597 & 1207 & 482 & 42 & 2117 & 18290 & 39197 & 2,4 \\
\hline Sari-sari & 140 & & & & & & & & & & & & 140 & 0,0 \\
\hline Sororoca & 527 & 144 & 466 & 1372 & 1284 & 16186 & 29251 & 8716 & 2734 & 320 & 222 & 2440 & 63660 & 4,0 \\
\hline Tainha & 223 & & 1059 & 1811 & 1675 & 4817 & 4200 & 3727 & 4476 & 1276 & 1235 & 362 & 24858 & 1,5 \\
\hline Tainha (ovada) & 167 & & & & 146 & 1791 & 349 & 989 & 598 & 46 & 50 & 6 & 4142 & 0,3 \\
\hline Trilha & & & & & & & & & 54 & & & & 54 & 0,0 \\
\hline Virote & 193 & 227 & 287 & 146 & 664 & 2645 & 1011 & 1397 & 1763 & 182 & 397 & 84 & 8995 & 0,6 \\
\hline Xerne & & & & & & & & 10 & & & & & 10 & 0,0 \\
\hline TOTAL & 46369 & 27971 & 51628 & 44195 & 44213 & 55340 & 73944 & 51680 & 50495 & 23307 & 80415 & 93037 & 642593 & 40 \\
\hline
\end{tabular}


Tabela 1 (continuação). Produção pesqueira total desembarcada em quilogramas, no município de Cananéia durante 1998

\begin{tabular}{|c|c|c|c|c|c|c|c|c|c|c|c|c|c|c|}
\hline Espécie & JAN & FEV & MAR & ABR & MAI & JUN & JUL & AGO & SET & OUT & NOV & DEZ & TOTAL & $\%$ \\
\hline \multicolumn{15}{|l|}{ Elasmobrânquios } \\
\hline Cação & 11318 & 1270 & 1026 & 578 & 275 & 639 & 1061 & 91 & 88 & & 3863 & 8084 & 28292 & 1,8 \\
\hline Cação-anjo & & & & & & 19 & 40 & 47 & 21 & 10 & 100 & 118 & 355 & 0,0 \\
\hline Cação-viola & 19 & 22 & 216 & 3 & & 4 & 1 & 12 & & & 371 & 360 & 1008 & 0,1 \\
\hline Caçonete & 607 & 350 & 336 & 356 & 78 & 30 & 231 & 6 & 18 & & 101 & 1771 & 3882 & 0,2 \\
\hline Cambeva-preto & & & & & & & & & & & & 225 & 225 & 0,0 \\
\hline Chup-chup & 1349 & 788 & 337 & & & & & 6 & 15 & 12 & 13 & 199 & 2719 & 0,2 \\
\hline Raia & 12 & 6 & 29 & & 51 & & 60 & 38 & 63 & & 42 & 31 & 331 & 0,0 \\
\hline TOTAL & 13305 & 2435 & 1943 & 937 & 404 & 692 & 1393 & 200 & 204 & 22 & 4490 & 10788 & 36811 & 2 \\
\hline \multicolumn{15}{|l|}{ Crustáceos } \\
\hline Camarão-branco & 850 & 3258 & 629 & 186 & 17514 & 11976 & 3996 & 1145 & 518 & 73 & 546 & 165 & 40855 & 2,5 \\
\hline Camarão-branco (rio ) & & 16 & 81 & 656 & 642 & 200 & 330 & 439 & 97 & & 14 & & 2475 & 0,2 \\
\hline Camarão-rosa & 107 & 138 & & & & & & 2295 & 1106 & 591 & 541 & 350 & 5127 & 0,3 \\
\hline Camarão-sete-barbas & 138406 & 126448 & 23892 & & 201199 & 128037 & 54798 & 15076 & 25456 & 37557 & 37598 & 27208 & 815675 & 50,8 \\
\hline Camarão-sete-barbas (escolhido) & 3706 & 1172 & & & 44 & 3356 & 3989 & 6618 & 3990 & 3795 & 15742 & 10528 & 52938 & 3,3 \\
\hline Lagosta & 23 & 9 & & & & & & 6 & & & & 26 & 64 & 0,0 \\
\hline TOTAL & 143091 & 131041 & 24602 & 842 & 219399 & 143569 & 63113 & 25580 & 31167 & 42015 & 54440 & 38276 & 917133 & 57 \\
\hline \multicolumn{15}{|l|}{ Moluscos } \\
\hline Caramujo & & & 10 & & & & & & & & & & 10 & 0,0 \\
\hline Lulas & 2080 & 5542 & & & & & & 18 & 42 & & & 534 & 8216 & 0,5 \\
\hline Polvos & 100 & 167 & & & & & & 539 & 977 & 81 & 108 & 147 & 2119 & 0,1 \\
\hline Vieira & & 15 & & & & & & 58 & 53 & 51 & & 7 & 184 & 0,0 \\
\hline TOTAL & 2180 & 5724 & 10 & 0 & 0 & 0 & 0 & 615 & 1072 & 132 & 108 & 688 & 10529 & 1 \\
\hline TOTAL DESEMBARCADO & 204946 & 167171 & 78183 & 45973 & 264015 & 199600 & 138449 & 78075 & 82938 & 65475 & 139453 & 142788 & 1607066 & 100 \\
\hline
\end{tabular}

Tabela 1 (continuação). Produção pesqueira total desembarcada em quilogramas, no município de Cananéia durante 1999

\begin{tabular}{|c|c|c|c|c|c|c|c|c|c|c|c|c|c|c|}
\hline Espécie & Jan & Fev & Mar & Abr & Mai & Jun & Jul & Ago & Set & Out & Nov & Dez & TOTAL & $\%$ \\
\hline \multicolumn{15}{|l|}{ Teleósteos } \\
\hline Abrótea & & & & & 18 & 52 & 273 & 339 & 404 & 200 & & & 1286 & 0,1 \\
\hline Anchova & & 16 & 163 & 178 & 55 & 183 & 695 & 485 & 102 & 10 & 316 & 36 & 2239 & 0,1 \\
\hline Atum & & & & 704 & 20 & & & & & & 41 & & 765 & 0,0 \\
\hline Badejo & 2 & & & 5 & & & 3 & & & & & & 10 & 0,0 \\
\hline Bagre & 350 & 673 & 631 & 955 & 544 & 875 & 1844 & 738 & 619 & 538 & 3168 & 2505 & 13440 & 0,6 \\
\hline Betara & 6323 & 13765 & 15552 & 9355 & 4192 & 5955 & 5888 & 6737 & 16454 & 17998 & 19164 & 18755 & 140137 & 6,6 \\
\hline Bonito & & & & 55 & & & & & & & 38 & 1090 & 1183 & 0,1 \\
\hline Cabrinha & & & & & & 500 & 6900 & 1538 & 469 & 245 & 1427 & 150 & 11229 & 0,5 \\
\hline Caranha & & & 2 & & & & & & & & & & 2 & 0,0 \\
\hline Carapau & & & & & & & & & & & & 3 & 3 & 0,0 \\
\hline Carapeba & 55 & 70 & 14 & 14 & 78 & 17 & 48 & 197 & 60 & 724 & 2790 & 1869 & 5935 & 0,3 \\
\hline Caraputanga & & 6 & & 7 & & & & & & & & & 13 & 0,0 \\
\hline Cascote & & 76 & 534 & 98 & 192 & 125 & 20 & 200 & 781 & 262 & 1051 & 630 & 3969 & 0,2 \\
\hline Cherne & & & & & & & & & 16 & 17 & 52 & & 85 & 0,0 \\
\hline Cioba & & & & & & & & & 109 & & & & 109 & 0,0 \\
\hline Congro-rosa & & & 33 & & & & & & & & & & 33 & 0,0 \\
\hline Corcoroca & & & & & & & & & & 19 & 1433 & 1316 & 2768 & 0,1 \\
\hline Corvina & 1529 & 2779 & 5961 & 6487 & 4232 & 18078 & 26784 & 36143 & 60840 & 36292 & 28520 & 17183 & 244828 & 11,6 \\
\hline Dourado & & & & 165 & 388 & & & & & & 205 & 25 & 783 & 0,0 \\
\hline Garoupa & 90 & 321 & 308 & 248 & 50 & 215 & 7 & 63 & 92 & 51 & 125 & 117 & 1686 & 0,1 \\
\hline Goete & & & 5275 & 1075 & 371 & 218 & 225 & 423 & 421 & 480 & 2217 & 514 & 11219 & 0,5 \\
\hline Gordinho & & & & & & & & & & & 160 & & 160 & 0,0 \\
\hline Guaivira & 4018 & 2919 & 10775 & 3965 & 2533 & 1448 & 2662 & 2326 & 2471 & 1693 & 6701 & 36340 & 77851 & 3,7 \\
\hline Linguado & & & 42 & 91 & 91 & 806 & 3282 & 5396 & 3637 & 2380 & 535 & 704 & 16962 & 0,8 \\
\hline Maria-mole & & & & & & & & & & & 26 & & 26 & 0,0 \\
\hline Marlym & & & & 483 & & & & & & & & & 483 & 0,0 \\
\hline Meca & & & 483 & & & & & & & & & & 483 & 0,0 \\
\hline Mero & & 18 & & & 130 & 15 & 11 & & & 57 & 51 & 77 & 359 & 0,0 \\
\hline Miraguaia & & & & & & 14 & 33 & 47 & & & & & 94 & 0,0 \\
\hline Mistura * & 3493 & 5087 & 8308 & 8386 & 3872 & 7788 & 27205 & 40837 & 34388 & 27607 & 24877 & 26107 & 217955 & 10,3 \\
\hline Namorado & & & & & & & 78 & & 10 & & & & 88 & 0,0 \\
\hline Olhete & & & & 10 & 60 & & & & & & & & 70 & 0,0 \\
\hline Oveva & & & & & & & & & & & & 136 & 136 & 0,0 \\
\hline Pacu & & & & 32 & & & & & & & & & 32 & 0,0 \\
\hline Pampo & 912 & 170 & 12 & 53 & 94 & 140 & 217 & & & & & 81 & 1678 & 0,1 \\
\hline Parati & 2853 & 4454 & 5903 & 4148 & 2630 & 2303 & 4062 & 2378 & 2525 & 2959 & 5178 & 3886 & 43278 & 2,0 \\
\hline Pargo-rosa & & & 124 & 22 & & & & 40 & 204 & 123 & & & 513 & 0,0 \\
\hline Paru & & 604 & 223 & 200 & 126 & 120 & & & & & & & 1273 & 0,1 \\
\hline Peixe-agulha & & & 421 & & & & & & & & & & 421 & 0,0 \\
\hline Peixe-espada & & 168 & 2815 & 967 & 962 & 70 & 345 & 569 & 661 & 103 & 550 & 906 & 8115 & 0,4 \\
\hline Peixe-galo & & & 1 & 1 & 6 & 32 & & 340 & & & & & 380 & 0,0 \\
\hline Peixe-porco & 1724 & 1000 & 165 & 1614 & 3040 & 4778 & 546 & 1732 & 1120 & 12400 & 14677 & 4602 & 47398 & 2,2 \\
\hline Peixe-roído & & 28 & 67 & 1266 & & 83 & 127 & 725 & 649 & 361 & 342 & 117 & 3765 & 0,2 \\
\hline Peixe-sapo & & & & & & & & & & & 23 & & 23 & 0,0 \\
\hline
\end{tabular}


Tabela 1 (continuação). Produção pesqueira total desembarcada em quilogramas, no município de Cananéia durante 1999

\begin{tabular}{|c|c|c|c|c|c|c|c|c|c|c|c|c|c|c|}
\hline Espécie & Jan & Fev & Mar & Abr & Mai & Jun & Jul & Ago & Set & Out & Nov & Dez & TOTAL & $\%$ \\
\hline \multicolumn{15}{|l|}{ Teleósteos } \\
\hline Pescada & 23 & 1160 & 165 & 532 & 10 & 5 & 62 & 1 & 503 & 4 & 1 & 80 & 2547 & 0,1 \\
\hline Pescada-amarela & 697 & 233 & 13 & 6 & & 41 & 30 & 21 & 3 & 234 & 159 & 630 & 2067 & 0,1 \\
\hline Pescada-banana & & & 12 & 12 & & 11 & & & & & 5 & 65 & 105 & 0,0 \\
\hline Pescada-bicuda & & & 87 & 16 & 86 & 251 & 38 & 50 & 51 & 106 & 295 & 74 & 1053 & 0,0 \\
\hline Pescada-branca & 80 & 170 & 1742 & 214 & 297 & 123 & 54 & 118 & 135 & 578 & 448 & 275 & 4234 & 0,2 \\
\hline Pescada-branca (média) & & & & & & 13 & & & & & & & 13 & 0,0 \\
\hline Pescada-cambucu & 200 & 451 & 1147 & 859 & 346 & 582 & 185 & 98 & 159 & 530 & 1696 & 1897 & 8150 & 0,4 \\
\hline Pescada-dentão & 73 & 167 & 23 & 24 & 117 & 138 & 484 & 130 & 89 & 51 & 544 & 333 & 2173 & 0,1 \\
\hline Pescada-foguete & 26809 & 35757 & 87698 & 50118 & 32962 & 23592 & 26311 & 28398 & 36839 & 29055 & 26710 & 28716 & 432965 & 20,5 \\
\hline Pescada-foguete (grande) & & & & & 158 & & & & & & 3 & & 161 & 0,0 \\
\hline Pescada-foguete (média) & & & & & 2 & & & & & & 27 & & 29 & 0,0 \\
\hline Pescada-foguete (pequena) & 64 & & & & 152 & 40 & & & & & 27 & & 283 & 0,0 \\
\hline Pescada-jaguara & & 2 & & 2 & & & & & & & & & 4 & 0,0 \\
\hline Pescadinha & 64 & & & 32 & & 150 & 5 & 70 & 800 & & & 718 & 1839 & 0,1 \\
\hline Piragica & & & & & 19 & & & 76 & 148 & & & & 243 & 0,0 \\
\hline Prejereba & 43 & 41 & 958 & 211 & 48 & 352 & 50 & 42 & 34 & 79 & 226 & 215 & 2296 & 0,1 \\
\hline Robalão & 41 & 40 & 40 & 114 & 86 & 33 & 84 & 9 & 56 & 87 & 139 & 540 & 1268 & 0,1 \\
\hline Robalete & 10 & & 44 & 54 & 7 & & 1 & 4 & 5 & 19 & 10 & 72 & 224 & 0,0 \\
\hline Robalinho & 7 & 1 & 19 & 16 & 1 & 8 & 1 & 2 & 5 & 41 & 159 & 168 & 428 & 0,0 \\
\hline Robalo & 132 & 360 & 209 & 127 & 30 & 92 & 48 & 91 & 27 & 96 & 483 & 250 & 1945 & 0,1 \\
\hline Sargo & 5 & & & & 80 & & & & & & & 240 & 325 & 0,0 \\
\hline Sari-sari & & & & & & & 49 & & & 46 & 143 & & 238 & 0,0 \\
\hline Sororoca & 29 & 191 & 529 & 888 & 2498 & 19926 & 5235 & 6890 & 825 & 2206 & 1126 & 749 & 41091 & 1,9 \\
\hline Tainha & 242 & 1030 & 1173 & 1605 & 4764 & 4754 & 2856 & 2326 & 2232 & 399 & 626 & 383 & 22391 & 1,1 \\
\hline Tainha (ovada) & 11 & & & & 1580 & 2508 & 573 & 253 & 306 & 131 & 6 & & 5368 & 0,3 \\
\hline Tira-vira & & & & & & & & 553 & 160 & & & & 713 & 0,0 \\
\hline Trilha & & & 40 & 92 & & & 1048 & 162 & 253 & 40 & 14 & 8 & 1657 & 0,1 \\
\hline Virote & 391 & 412 & 392 & 527 & 2188 & 2766 & 2535 & 1120 & 1212 & 426 & 215 & 121 & 12305 & 0,6 \\
\hline Xaréu & 27 & & & 148 & & 5 & & 370 & & & & & 550 & 0,0 \\
\hline TOTAL & 50297 & 72169 & 152103 & 96181 & 69112 & 99204 & 120899 & 142034 & 169871 & 138646 & 146729 & 152680 & 1409925 & 67 \\
\hline \multicolumn{15}{|l|}{ Elasmobrânquios } \\
\hline Cação & 918 & 761 & 1722 & 3995 & 2223 & 686 & 690 & 511 & 527 & 5262 & 5893 & 15873 & 39061 & 1,8 \\
\hline Cação-anjo & & & & 575 & 14 & 412 & 526 & 545 & 1071 & 1959 & 848 & 675 & 6623 & 0,3 \\
\hline Cação-chup-chup & 364 & 88 & 256 & 685 & 171 & 5 & & & & 81 & 587 & 1106 & 3343 & 0,2 \\
\hline Cação-viola & 2 & 41 & 77 & & 66 & & 61 & 74 & 40 & 15 & 179 & 110 & 665 & 0,0 \\
\hline Caçonete & 503 & 1164 & 447 & 538 & 121 & 236 & 459 & 744 & 61 & 137 & 1414 & 2329 & 8152 & 0,4 \\
\hline Cambeva & & & & & & 28 & & & & & 80 & & 108 & 0,0 \\
\hline Raia & & & 261 & 455 & 210 & & 20 & 524 & 149 & 315 & 390 & 42 & 2365 & 0,1 \\
\hline \multirow[t]{2}{*}{ Raia-emplasto } & & & 77 & 237 & & & & & & & & & 314 & 0,0 \\
\hline & & & & & & & & & & & & & 0 & 0,0 \\
\hline TOTAL & 1787 & 2054 & 2840 & 6485 & 2805 & 1366 & 1756 & 2396 & 1847 & 7768 & 9390 & 20135 & 60630 & 3 \\
\hline
\end{tabular}

Tabela 1 (continuação). Produção pesqueira total desembarcada em quilogramas, no município de Cananéia durante 1999

\begin{tabular}{|c|c|c|c|c|c|c|c|c|c|c|c|c|c|c|}
\hline Espécie & Jan & Fev & Mar & Abr & Mai & Jun & Jul & Ago & Set & Out & Nov & 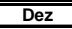 & TOTAL & $\%$ \\
\hline \multicolumn{15}{|l|}{ Crustáceos } \\
\hline Camarão-legítimo & 217 & 228 & & & 1237 & 799 & 723 & 281 & 260 & 36 & 119 & 71 & 3970 & 0,2 \\
\hline Camarão-legítimo (rio) & 116 & 184 & 1962 & 962 & 172 & & 1 & & 57 & & & 360 & 3814 & 0,2 \\
\hline Camarão-mole & & & & & & & 36 & & & & & & 36 & 0,0 \\
\hline Camarão-rosa & 280 & & & & 331 & 820 & 5379 & 4397 & 3525 & 1833 & 1323 & 1494 & 19382 & 0,9 \\
\hline Camarão-rosa-perereca & 20 & & & & & & & & & & 5 & 26 & 51 & 0,0 \\
\hline Camarão-sete-barbas & 70503 & 75988 & & & 70875 & 74733 & 30161 & 17666 & 22858 & 43574 & 20948 & 39432 & 466737 & 22,1 \\
\hline Camarão-sete-barbas (descabeçado) & & & & & & & & & & & 111 & 29 & 140 & 0,0 \\
\hline Camarão-sete-barbas (escolhido) & 18824 & 1501 & & & 4236 & 3843 & 7368 & 10919 & 13591 & 27045 & 21531 & 12555 & 121412 & 5,7 \\
\hline Camarão-sete-barbas (miúdo) & & & & & & & & & & & & 244 & 244 & 0,0 \\
\hline Lagosta & 76 & & & & 1 & 2 & 6 & & & 5 & & & 89 & 0,0 \\
\hline Lagostim & & & & & & & 8,0 & & & & & & 8 & 0,0 \\
\hline TOTAL & 90036 & 77901 & 1962 & 962 & 76851 & 80197 & 43681 & 33263 & 40290 & 72492 & 44037 & 54210 & 615882 & 29 \\
\hline \multicolumn{15}{|l|}{ Moluscos } \\
\hline Lula & 3426 & 6000 & 6260 & 9 & & & & & 179 & 309 & 384 & 782 & 17349 & 0,8 \\
\hline Polvo & 26 & & 290 & 51 & 68 & 330 & 1732 & 1346 & 1383 & 962 & 642 & 936 & 7766 & 0,4 \\
\hline Vieira & & & 8 & 10 & 70 & & 6 & 269 & 129 & 34 & 13 & 76 & 615 & 0,0 \\
\hline & & & & & & & & & & & & & & 0,0 \\
\hline TOTAL & 3452 & 6000 & 6558 & 70 & 138 & 330 & 1738 & 1615 & 1691 & 1305 & 1039 & 1794 & 25730 & $\mathbf{1 , 2}$ \\
\hline TOTAL DESEMBARCADO & 145572 & 158124 & 163463 & 103698 & 148906 & 181097 & 168075 & 179309 & 213699 & 220211 & 201195 & 228819 & 2112167 & 100 \\
\hline Caramujo (unidade) & & & & & & & & & & 90 & & & 90 & \\
\hline Caranguejo-uçá (dúzia) & & & & 420 & 595 & 310 & 600 & 370 & & & & 375 & 2670 & \\
\hline Mexilhão (litro) & & & & 1638 & 2628 & 1309 & 3206 & 1992 & 2328 & 2608 & 2990 & 2050 & 20749 & \\
\hline Ostra (dúzia) & & 306 & 480 & 15084 & 22485 & 28892 & 31916 & 26753 & 26173 & 22585 & 22885 & 16440 & 213999 & \\
\hline Ostra-limpa (pacote) & & & & & 20 & 30 & & 1 & & & & & 51 & \\
\hline Siri-azul (dúzia) & & & & & & & & & 47 & & & & 47 & \\
\hline
\end{tabular}


haja escolha de camarão a bordo dos barcos maiores (baleeiras), pois o trabalho, segundo os pescadores não compensa, como ocorre no segundo semestre. Devido ao esforço pesqueiro sobre indivíduos menores, como ocorre, principalmente no primeiro trimestre, poderá haver sobrepesca do recurso, visto a diminuição de indivíduos que irão recrutar no segundo semestre. De acordo como Severino-Rodrigues (1992) o recrutamento ocorre todo $o$ ano, fato confirmado por nós, pois encontramos indivíduos abaixo de $6 \mathrm{~cm}$ em todos os meses, mas 0 pico de indivíduos com menores comprimentos coincidem com os maiores desembarques, indicando que há um esforço sobre espécimes juvenis, período este indicado para um defeso, aumentando as chances de manter o recurso.

O camarão escolhido desembarcado apresenta um comprimento médio em torno de $9 \mathrm{~cm}$, sendo descartado ao mar os indivíduos menores. Estes não são trazidos aos pontos de desembarque devido as dificuldades de comércio, não compensando seu transporte, uma vez que, o valor pago é abaixo de $R \$ 0,50$ por quilograma e/ou não encontraram comprador.

O valor médio do camarão-sete-barbas pago ao pescador, depende do número de pe- ças ou comprimento médio. Cabe salientar que estes valores oscilam muito ao longo do ano, dependendo da disponibilidade do produto no comércio. Este fato faz com que haja a seleção do produto a bordo ou não, aumentando a rejeição do camarão ao longo do ano.

Na pesca de camarão escolhido a proporção, de acordo com os pescadores chega a ser de $3 \mathrm{~kg}$ de camarão rejeitado para $1 \mathrm{~kg}$ de camarão selecionado, ou seja $25 \%$ do camarão capturado é aproveitado, podendo variar ao longo do ano. É imprescindível saber de quanto é exatamente o rejeito deste camarão ao longo do ano e quais áreas ocorre maiores descartes, visto que de acordo com GraçaLopes (1996) os camarões se distribuem em diferentes tamanhos na plataforma. Para administrar a pesca e determinar quanto o recurso está sendo explorado é necessária a quantificação de tais capturas, podendo estimar o impacto que a população de camarãosete-barbas está sofrendo.

Embora existam várias tentativas de diminuir a ocorrência de indivíduos pequenos, o Xiphopenaeus kroyericomeça a ser capturado a partir da classe de comprimento de $1,5 \mathrm{~cm}$, com grandes incidências entre os comprimen-

ton

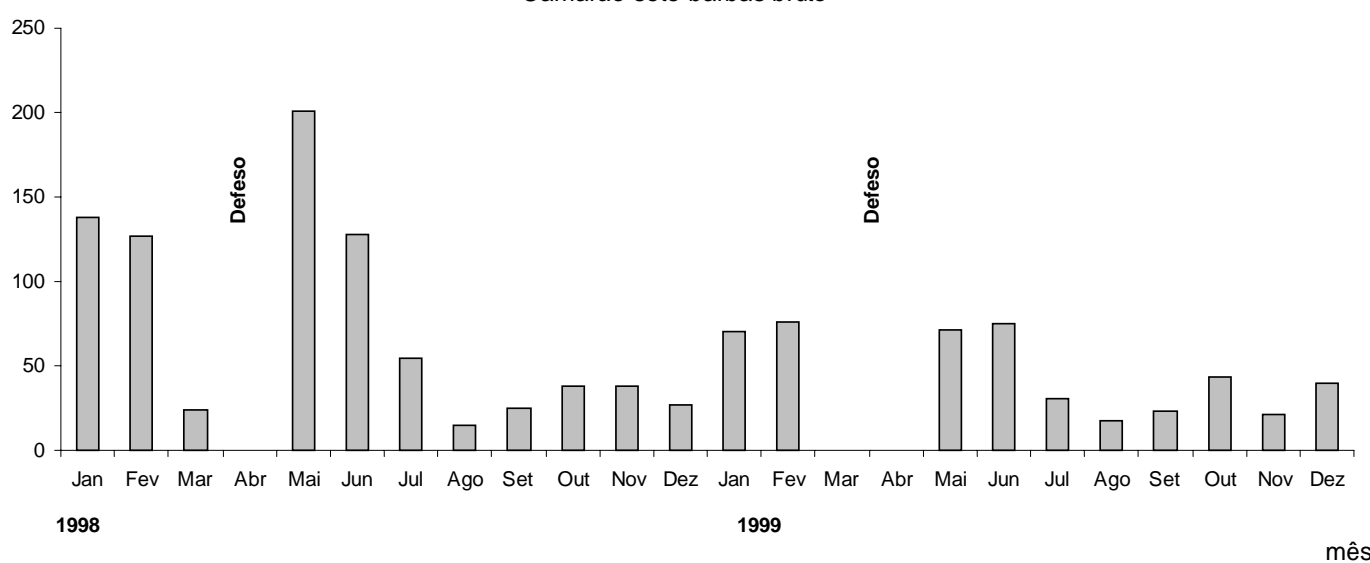

Figura 2. Produção desembarcada de camarão-sete-barbas bruto durante 1998 e 1999. 
tos de 4,0 a 9,0 cm (Severino-Rodrigues et al., 1992), fato que foi comprovado por nossos dados, que temos o $\mathrm{L}_{50} \mathrm{em} 8,0 \mathrm{~cm}$ para ambos os anos (figura 5). Como o tamanho de primeira maturação do camarão-sete-barbas está entre $6,0 \mathrm{~cm}$ a $7,0 \mathrm{~cm}$, dependendo do sexo (Severino-Rodrigues et al., op. cit.), vemos que a frota pesqueira de Cananéia trabalha sobre boa parcela de indivíduos com tamanho de primeira maturação. Dos desembarques de camarão bruto a frota captura entorno de $31 \%$ de indivíduos com tamanho de primeira maturação ou inferiores.

Analisando a captura por unidade de esforço, mostrou-se que os maiores rendimentos ocorreram no primeiro semestre (figura 6), com a média anual de $18 \mathrm{~kg} / \mathrm{hora}$ em $1998 \mathrm{e}$ 16,2 kg/hora em 1999. De acordo Graça-Lopes (1996) os rendimentos máximos sustentável encontrado foi de $19,7 \mathrm{~kg} / \mathrm{hora}$, assim, conforme os desembarques de Cananéia o rendimento está quase em seu limite, semelhantes há anos anteriores (Mendonça, 1998), mas encontramos quedas na CPUE entre 1997, que atingiu $21 \mathrm{~kg} /$ hora (Mendonça et al. 1998) para 1999 de $25 \%$, assim isto pode sugerir que estes rendimentos encontrados para os anos de 1998 e
1999 não indicam necessariamente que o estoque está estável.

O período de defeso estipulado atualmente para os camarões, visa essencialmente a proteção dos juvenis de camarão-rosa (Farfatepenaeus brasiliensis e F. paulensis), visto que coloca o defeso no período de recrutamento das espécies (fevereiro a maio). Possivelmente para efetivar a fiscalização foi incluída a proibição de outras espécies de camarões que atuam na plataforma, pois fica difícil o policiamento das embarcações do rosa, com a liberação da atividade de pesca de outras espécies de camarões, visto que as embarcações também podem trabalhar na captura do rosa. Então, a portaria em vigor inclui todas espécies de camarões comerciais da plataforma continental das regiões sudeste e sul do Brasil. Embora para o camarão rosa o período de defeso esteja razoavelmente correto, outros fatores fazem com que o recurso continue a diminuir como o tamanho da frota e fiscalização pouco efetiva (Valentini, 1991; IBAMA, 1993). Graça-Lopes (1996), mostrou em suas análises, que 0 ordenamento das capturas de camarão-sete-barbas está ineficiente para a manutenção do estoque. Para o camarão-sete-

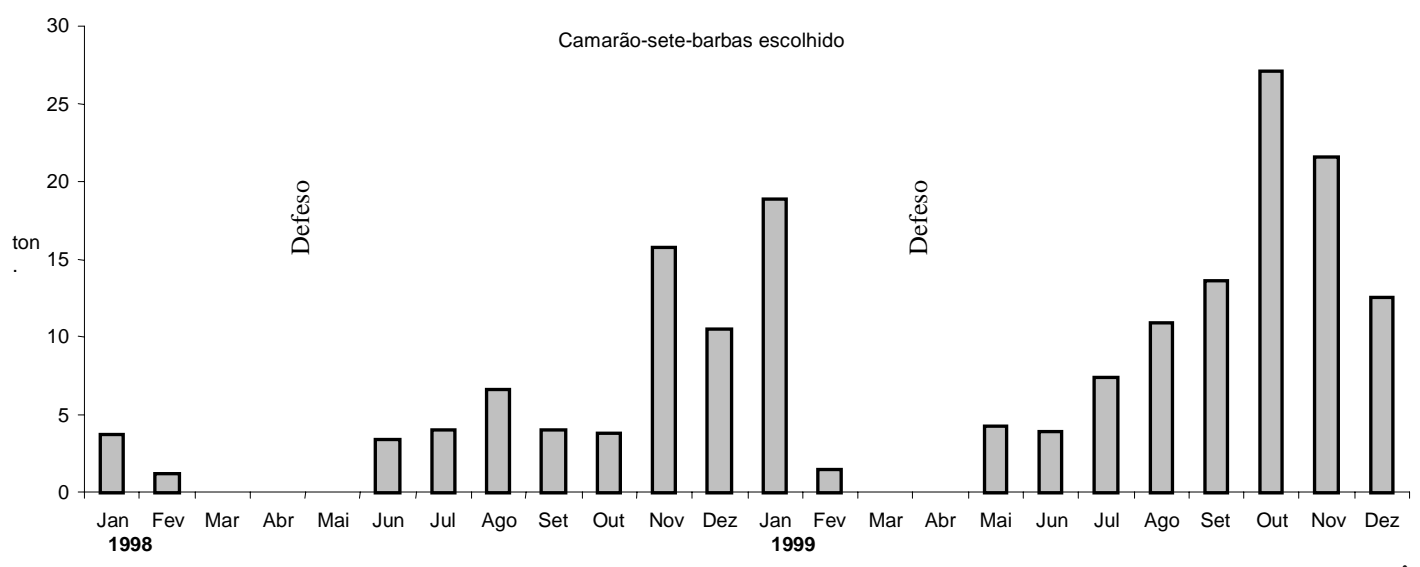

Figura 3. Produção desembarcada de camarão-sete-barbas escolhido durante 1998 e 1999. 

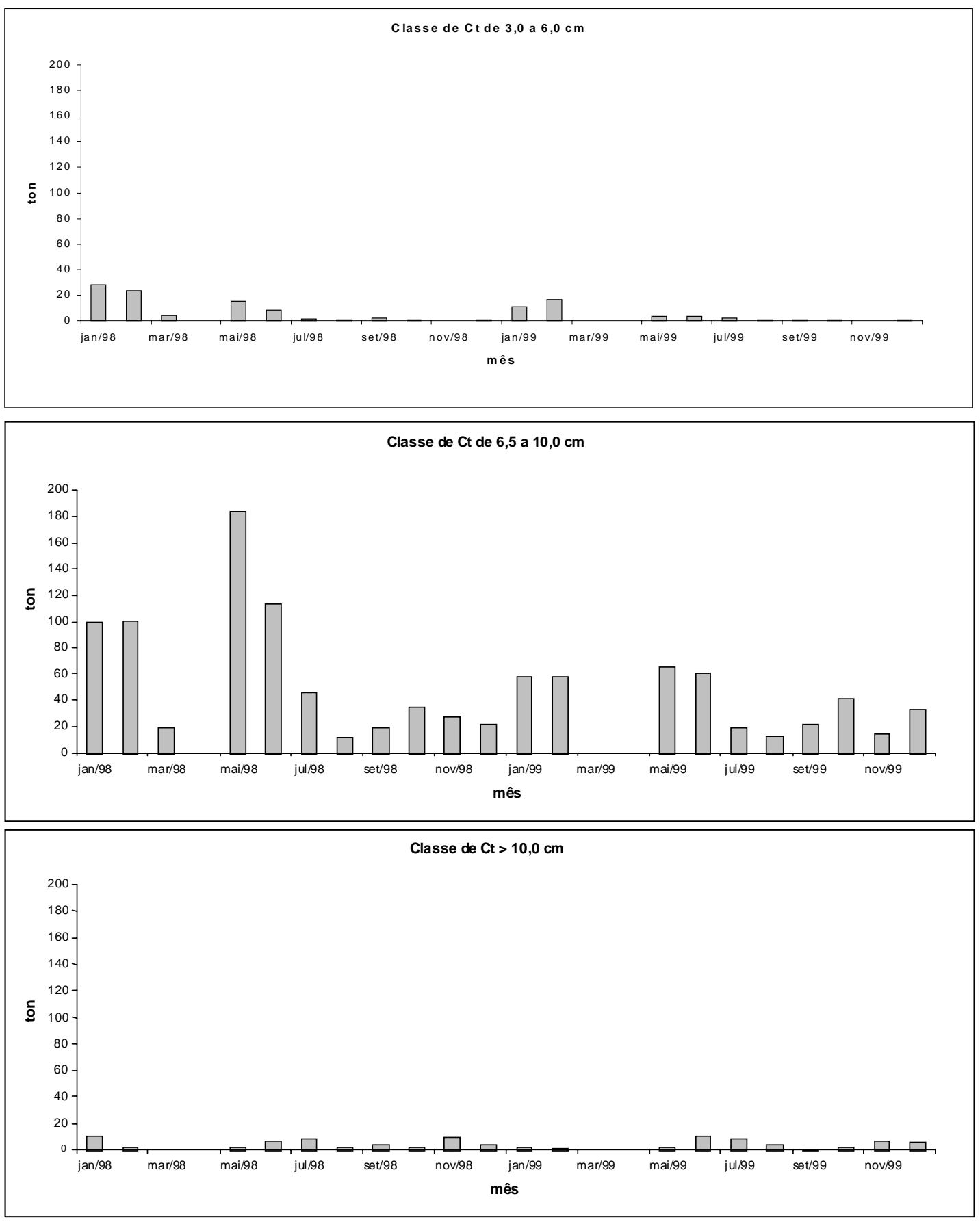

Figura 4. Produção desembarcada mensal por classe de comprimento do camarão-sete-barbas durante os anos de 1998 e 1999 
barbas, visando a proteção do principal período de recrutamento a portaria está equivocada, visto que a maior incidência de indivíduos pequenos encontra-se no primeiro trimestre do ano. De acordo com os dados de Cananéia, 0 defeso teria melhores resultados durante o período de recrutamento, pois é o momento de maiores capturas e menores indivíduos, assim diminuiria o esforço sobre o recurso e protegeria o principal período de recrutamento do camarão-sete-barbas. Mas um fato a ser repen- sado são os aspectos sociais, que desde muito estão sendo citados (IBAMA, 1993) os quais pouco levados em consideração, visto que uma paralisação de uma frota pesqueira do tamanho da camaroneira gerará impactos sócio-econômicos de difícil solução, como por exemplo a falta de amparo financeiro aos pescadores, como crédito para compra de outras artes de pesca, adequação das embarcações entre outros.
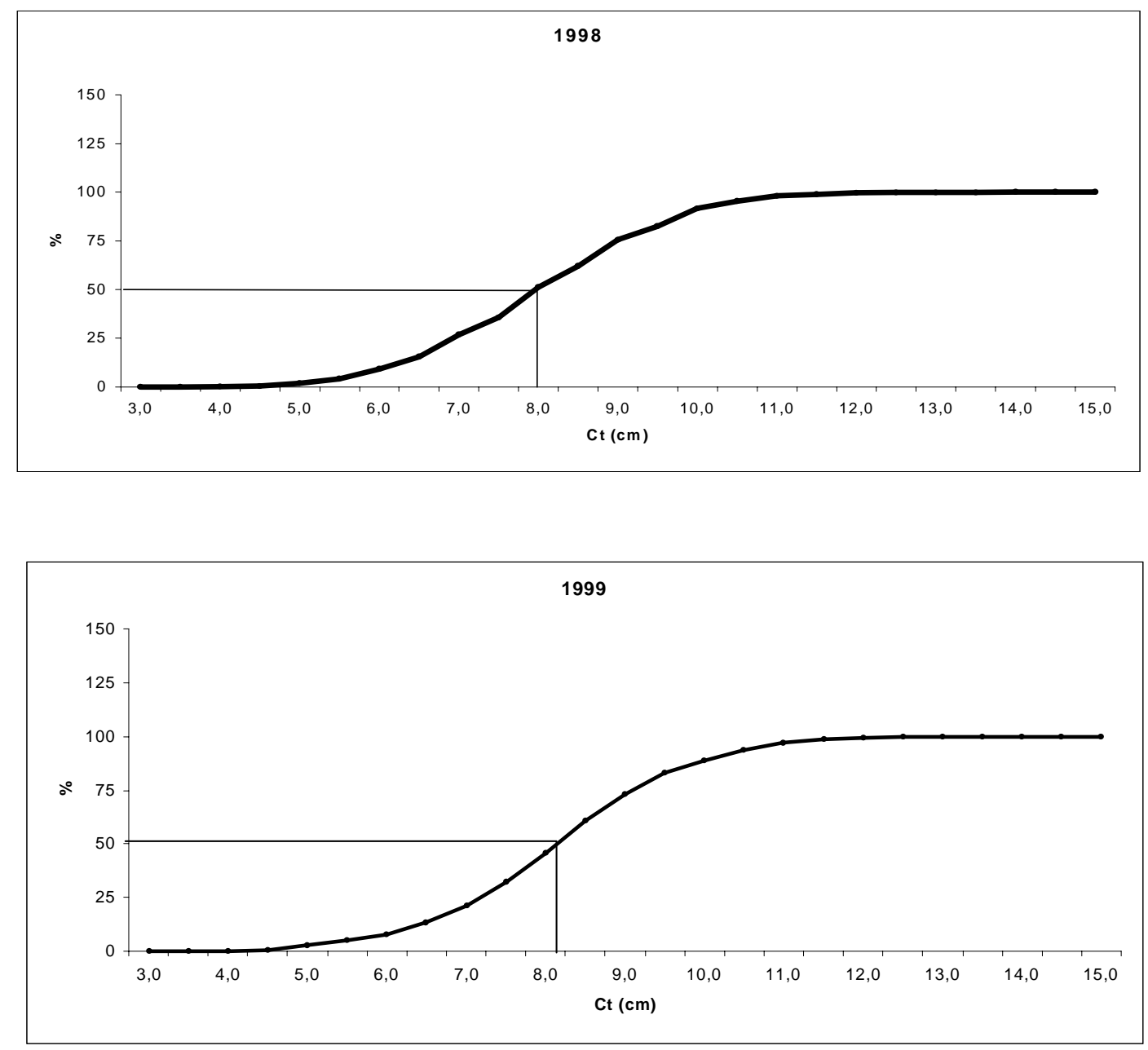

Figura 5. Distribuição de freqüência acumulada de comprimentos de camarão-sete-barbas nos anos de 1998 e 1999. 
Poderíamos sugerir o defeso no período reprodutivo, sendo em meados de outubro a dezembro (Severino-Rodrigues, et al., 1992), mas acarretaria problemas sociais e econômicos no abastecimento do comércio, visto que indica-se o momento de aquecimento da economia com a entrada de períodos com maior fluxo turístico. Outro fato é que, de acordo com os dados de Cananéia, o segundo semestre, já mostra-se com menores esforço pesqueiro sobre o camarão-sete-barbas, apresentando maior direcionamento da frota à pesca de camarão-rosa, o qual apresenta maior rendimento econômico ao pescador, então pouco diminuiria o esforço pesqueiro sobre o recurso.

\section{CONCLUSÕES}

Os desembarques de camarão-sete-barbas no município de Cananéia durante os anos
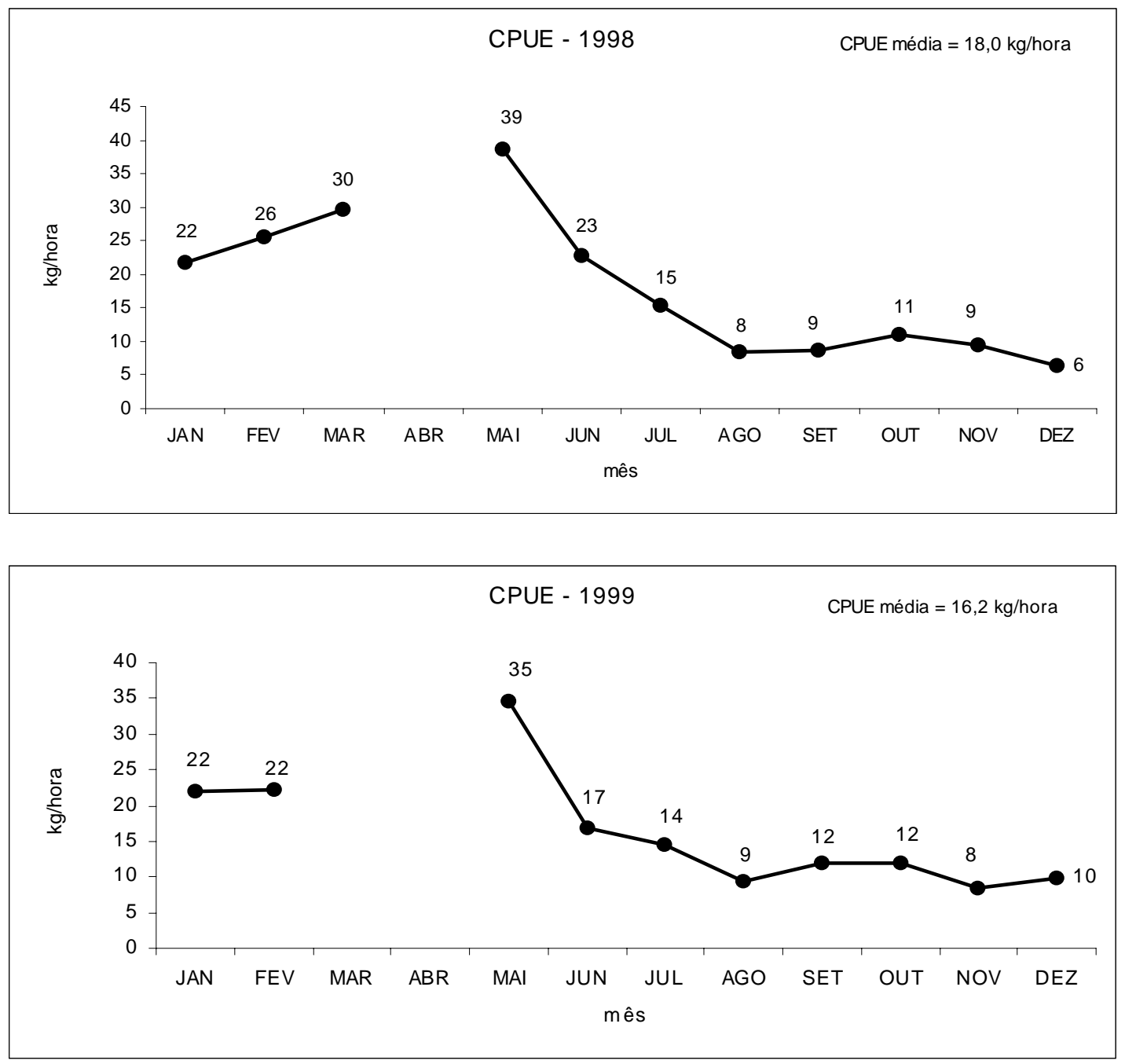

Figura 6. Captura por unidade de esforço mensal do camarão-sete-barbas em kg/hora, durante os anos de 1998 e 1999. 
de 1998 e 1999 foi de 869 e 589 toneladas, respectivamente. As categorias de comércio durante estes anos foram divididas entre camarão-sete-barbas bruto (sem seleção a bordo), camarão-sete-barbas escolhido (com seleção), camarão-sete-barbas descabeçado (com seleção e posterior processamento) e camarão-sete-barbas miúdo (com seleção, sendo retirado os maiores).

Ao longo do ano, as maiores produções de camarão ocorrem no primeiro semestre, com os indivíduos de comprimento médio menores. No segundo semestre diminui a produtividade, mas os indivíduos apresentam comprimentos médios maiores.

No segundo semestre ocorre os maiores desembarques de camarão-sete-barbas escolhido, havendo o aumento da rejeição, em detrimento da maior ocorrência de indivíduos maiores devido ao período de desova (Graça Lopes, 1996).

O período atual de defeso do camarãosete-barbas tem que ser reavaliado, pois o índice de abundância está no limite suportável para a população, mostrando sinais de queda até 1999.

A análise da composição da rejeição junto à pesca artesanal é necessária, com o intuito de melhorar a administração pesqueira e o aproveitamento racional das capturas.

\section{BIBLIOGRAFIA}

Assumpção, R.; Cardoso, E.S. \& N. Giulietti. 1996. Situação da pesca artesanal marítima no município de São Sebastião. Inst. de Economia Agrícola. Informações Econômicas, Vol. 26(5): 19-28.

Ávila-Da-Silva, A.O.; Carneiro, M.A.H. \& L. Fagundes. 1999. Gerenciador de banco de controle estatístico de produção pesqueira marítima - ProPesq® in: XI Congresso Brasileiro de Engenharia de Pesca - I Congresso Latino Americano de Engenharia de Pesca, Recife. Anais - Proceeding... Vol. 2. P: 824-832.
García, S. \& L. Le Reste., 1987. Ciclos vitales, dinámica, exploración y ordenación de las poblaciones de camarones peneidos costeros. FAO Doc. Téc. Pesca (203):180 p.

Graça-lopes, R. 1996. A pesca do camarãosete-barbas Xiphopenaeus kroyeri (Heller, 1862) e sua fauna acompanhante no litoral do Estado de São Paulo. Tese de Doutorado em Ciências Biológicas, apresentada ao Instituto de Biociência da UNESP, campus Rio Claro. $96 \mathrm{p}$.

Haimovici, M. \& J.T. Mendonça, 1996a. Análise da pesca de arrasto de tangones de peixes e camarões no sul do Brasil - período de 1989-1994. Atlântica, Rio Grande, 18:143-160.

Haimovici, M. \& J.T. Mendonça, 1996 b. Descartes da fauna acompanhante na pesca de arrasto de tangones dirigida a linguados e camarões na plataforma continental do sul do Brasil. Atlântica, Rio Grande, 18:161-178.

IBAMA, 1993. Relatório da reunião técnica sobre camarões das regiões sudeste e sul do Brasil. MMAA/IBAMA-DIRPED/ CEPSUL. $19 \mathrm{p}$.

Mendonça, J.T. 1998. A pesca na região de Cananéia, nos anos de 1995 e 1996. Dissertação de Mestrado. Oceanografia Biológica, Instituto Oceanográfico - USP, São Paulo. 120 p.

Mendonça, J.T.; Pires, A.D.; Calasans, G.C. \& S.C. Xavier. 1998. Relatório Anual da Atividade Pesqueira do Município de Cananéia em 1997. Documento Técnico de Divulgação. Instituto de Pesca - SAA, Cananéia, SP, 45p.

Peres, J.A.A.; Lucato, S.H.B.; Andrade, A.H.; Pezzuto, P.R. \& M. Rodrigues-Ribeiro. 1998. Programa de amostragem da pesca industrial desenvolvido para o porto de Itajaí, SC. Notas Tec. FACIMAR, 2:93-108.

Severino Rodrigues, E.; Pita, J.B.; Graça Lopes, R.; Coelho, J.A.P. \& A. Puzzi. 1992. Aspectos biológicos e pesqueiros do cama- 
rão sete-barbas (Xiphopenaeus kroyerı) capturado pela pesca artesanal no litoral do estado de São Paulo. Bolm. Inst. Pesca 19(único) : 67 - 81.

Tiago, G.G.; Tutui, S.L.S.; Seckendorff, R.W. Von; Grassi, R.T.B. \& M.L.S. Inácio. 1995. Análise da frota pesqueira sediada em Ubatuba, estado de São Paulo, Brasil. B. Inst. Pesca, 22(2): 71-83.
Valentini, H.; D'incao, F.; Rodriguez, L.F.; Rebelo-Neto, J.E. \& L.G. Domit. 1991. Análise da pesca do camarão sete-barbas (Xiphopenaeus kroyeri) nas regiões sudeste e sul do Brasil. Atlântica, Rio Grande, Brasil 13(1) : 171 - 178. 